\title{
THE PREVALENCE OF CIGARETTE SMOKING AND ITS RELATION TO CERTAIN RISK PREDICTORS OF CARDIOVASCULAR DISEASES IN CENTRAL- SLOVAKIAN ROMA CHILDREN AND ADOLESCENTS
}

\author{
Zuzana Hujová', Roman Alberty¹, Edita Paulíková2, Ivan Ahlers², Eva Ahlersová2, Drahoslav Gábor, \\ Michael Dove ${ }^{4}$ \\ 1Department of Biology, Faculty of Science, Matthias Belius University, Banská Bystrica, Slovakia \\ ${ }^{2}$ Institute of Biology and Ecology, Faculty of Science, Pavol Jozef Šafárik University, Košice, Slovakia \\ ${ }^{3}$ Department of Clinical Biochemistry, F. D. Roosevelt Faculty Hospital, Banská Bystrica, Slovakia \\ ${ }^{4}$ Department of English and American Studies, Faculty of Humanities, Matthias Belius University, Banská Bystrica, Slovakia
}

\section{SUMMARY}

The objective of the study was to determine some Cardiovascular Disease (CVD) risk factors in relation to cigarette smoking in 174 Roma children and adolescents (88 males and 86 females) and 131 non-Roma probands (males and females) aged 7-18 in central Slovakia.

In this biethnic study, $26.4 \%$ of the Roma children and adolescents (more than twice contrary to the control group) were smokers. Among the studied ethnicities, the majority of smokers was Roma ( $79.3 \%, 46$ subjects). Smoking Roma have higher means of TG, Lp(a) and WHR compared with non-smoking non-Roma. The most frequent CVD risk predictors of smoking Roma probands was low serum levels HDL-C, apo A (the Fisher test confirmed a significant relationship between cigarette smoking and HDL-C, apo A; $p<0.01$ ).

The results of the research should help to develop an effective preventative health education programs focused on Roma education (who live in a higher-risk environment compared to the majority population) in order to stem the spread of CVD as well as morbidity and mortality in this ethnic group living in Slovakia.

Key words: Roma, children, adolescents, cigarette smoking, cardiovascular risk factors

Address for correspondence: Z. Hujová, Department of Biology Faculty of Science, Matthias Belius University, Tajovského 40, Banská Bystrica 974 01, Slovakia. E-mail: zuzana.hujova@gmail.com

\section{INTRODUCTION}

Cigarette smoking is the one of modifiable risk factors contributing to the development of atherosclerosis (1). Cigarette smoking is known to cause of $17-30 \%$ of deaths due to cardiovascular disease (2). Cigarette initiates endothelial destructions in atherogenesis disturbes regulation of vascular tonus, thrombocyte-endothelial interactions, increases aggregability of thrombocytes, decreases prostacyclin production, causes the increase of adhesion and elevation of leucocytes' count, proliferation of smooth-muscle cells, the increase of C-reactive protein levels and synthesis of inactive $\mathrm{NO}$ (3). Cigarette smoking negatively modifies the serum lipid profile (two-fold increase of total cholesterol concentration, the decrease of HDL-cholesterol - HDL-C levels and oxidation of LDL-cholesterol - LDL-C). In addition, nicotine causes the elevation of adherence of monocytes to the endothelium, increase of blood pressure (BP), catecholamine levels stimulating heart activity.

With regard to health problems, Roma is the ethnic group with higher risky behaviour in Slovakia (4). Overweight, unhealthy nutrition, bad lifestyle and high prevalence of cigarette smoking initiated at an early age lead to more frequent diabetes mellitus II., metabolic syndrome, hypertension, obesity, hypertriglyceridaemia and hypercholesterolaemia in adult Roma in comparison to the general population (5), which result in higher morbidity and mortality.

The lack of information about the health status of centralSlovakian Roma children and adolescents prompted us to monitor the conditions leading later to an early onset and development of atherosclerosis and cardiovascular diseases in this ethic group.

The objective of this study is to describe CVD risk predictors of the Roma population with respect to cigarette smoking prevalence in its relation to anthropometric (body mass index - BMI, waist to hip ratio - WHR as markers of obesity, BP for classification of hypertension) and biochemical (total cholesterol - TC, LDL-C, HDL-C, triglycerides - TG, apolipoprotein A - apo A, apolipoporotein $B-$ apo B, lipoprotein a $-\mathrm{Lp}(\mathrm{a})$ ) risk factors, with a view to ethnic-, gender- and age-specific differences.

\section{MATERIAL AND METHODS}

\section{Examined Population}

The target population was represented by 174 Roma participants (including 88 males and 86 females) and non-Roma participants $(n=131)$, between the age of 7 and 18. Some 
subjects are part of a larger cross-sectional biethnic study on the prevalence of CVD in childhood and thus were reported on previously (6).

Participants provided blood samples and underwent physical examination which took place at Central Slovakian Pediatric Health Centres in 2003-2006. Examined subjects were divided into two age categories: 7-11 years (children) and $12-18$ years (adolescents). Randomly selected individuals (198 Roma; but only children and adolescents without missing data were used in this report $n=174$ ) were representatives of a healthy population (all subjects with illnesses, which could influence the results - hypercholesterolemia, hypertriglyceridemia, diabetes, endocrine disorders or inadequate function of the kidneys - were excluded).

\section{METHODS}

Subjects' current smoking habits (or lack of) were determined by a questionnaire. Smoking status was assessed quantitatively, using the number of cigarettes smoked weekly according to self-reported data. Measurements regularly used in paediatric practices (such as height, weight, waist and hip circumference) were obtained for each subject. BP was measured on the right arm in a seated position by mercury sphygmomanometer with mmHg scale (evaluated $\mathrm{sBP}>120$ $\mathrm{mmHg}, \mathrm{dBP}>80 \mathrm{mmHg}$ ). BMI, used for assessment of the prevalence of obesity (BMI $>24.50 \mathrm{~kg} \cdot \mathrm{m}^{-2}$ for 7-11 yrs female, BMI $>28.52 \mathrm{~kg} . \mathrm{m}^{-2}$ for $12-18$ yrs female and BMI $>25.13$ $\mathrm{kg} \cdot \mathrm{m}^{-2}$ for $7-11 \mathrm{yrs}$ male, BMI $>28.82 \mathrm{~kg} \cdot \mathrm{m}^{-2}$ for $12-18 \mathrm{yrs}$ male as recommended by (7), was calculated as a quotient of weight and squared height in meters $\left(\mathrm{kg} . \mathrm{m}^{-2}\right)$ and WHR as derived waist to hip circumference. Waist circumference was measured in the middle between the arch of 10th rib and the top of crista iliaca (WHR 0.90 for female and WHR $>0.85$ for male). Blood was drawn between 8.00 am and 9.30 am after a 12 hour overnight fasting. Samples were analyzed in the biochemical laboratory of Roosevelt Hospital in Banská Bystrica. Blood serum levels TC, HDL-C and TG were determined enzymatically, concentration of LDL-C was calculated by the Friedewald Formula: LDL-C = TC-(HDL-C + TG/2.2). Glucose levels were not analyzed.Serum levels of apolipoproteins (apo A, apo B) were analyzed imunochemically. Concentration of $\mathrm{Lp}$ (a) was analyzed by immunonephelometric method (Beckman-Coulter System). For comparison and evaluation of obtained results, values, which have been recommended by Czech society for atherosclerosis ( $\mathrm{TC} \geq 5 \mathrm{mmol} / \mathrm{l}, \mathrm{TG} \geq 1.5$ $\mathrm{mmol} / \mathrm{l}, \mathrm{LDL}-\mathrm{C} \geq 3.4 \mathrm{mmol} / \mathrm{l}$, HDL-C $\leq 1 \mathrm{mmol} / \mathrm{l}$ ) were used. We used an evaluation of apolipoproteins (8) and lipoprotein a by Šimurka. A "p" value $<0.05$ was considered as significant. The Fisher Exact Test was used to evaluate the relationship of CVD risk factors and lifestyle factors. Statistical analyses were performed using the SPSS System software package.

\section{RESULTS}

\section{Subject Sample Profiles and CVD Predictors}

The results of the study consist of two parts. The first part includes a profile of Roma and non-Roma children and adolescents in terms of the correlation between rates of cigarette smoking and ethnic, gender and age differences. The second section contains an evaluation of the correlation of cigarette smoking with other CVD risk predictors in Roma and nonRoma participants.

Table 1. The prevalence of cigarette smoking by ethnic, gender and age-related differences

\begin{tabular}{|c|c|c|c|}
\hline \multicolumn{2}{|c|}{ Ethnic-, gender- and age- characteristics } & $\begin{array}{c}\text { Smoking } \\
\text { participants }\end{array}$ & $\begin{array}{l}\text { Non-smoking } \\
\text { participants }\end{array}$ \\
\hline \multicolumn{4}{|l|}{ Roma (n=174) } \\
\hline \multirow[b]{3}{*}{ Males $(n=88)$} & $7-11(n=30)$ & $6.7 \%(2)$ & $93.3 \%(28)$ \\
\hline & $12-18(n=58)$ & $46.6 \%(27)$ & $53.4 \%(31)$ \\
\hline & all & $33 \%(29)$ & $67 \%(59)$ \\
\hline \multirow[b]{3}{*}{ Females $(n=86)$} & $7-11(n=27)$ & $3.7 \%(1)$ & $96.3 \%(26)$ \\
\hline & $12-18(n=59)$ & $27.1 \%(16)$ & $72.9 \%(43)$ \\
\hline & all & $19.8 \%(17)$ & $80.2 \%(69)$ \\
\hline \multicolumn{2}{|l|}{ Roma } & $26.4 \%(46)$ & $73.6 \%(128)$ \\
\hline \multicolumn{4}{|c|}{ Non-Roma $(n=131)$} \\
\hline \multirow[b]{3}{*}{ Males $(n=67)$} & $7-11(n=28)$ & - & $100 \%(28)$ \\
\hline & $12-18(n=39)$ & $12.8 \%(5)$ & $87.2 \%(34)$ \\
\hline & all & $7.5 \%(5)$ & $92.5 \%(62)$ \\
\hline \multirow[b]{3}{*}{ Females $(n=64)$} & $7-11(n=27)$ & $3.7 \%(1)$ & $96.3 \%(26)$ \\
\hline & $12-18(n=37)$ & $16.2 \%(6)$ & $83.8 \%(31)$ \\
\hline & all & $10.9 \%(7)$ & $89.1 \%(57)$ \\
\hline \multicolumn{2}{|l|}{ Non-Roma } & $9.2 \%(12)$ & $90.8 \%(119)$ \\
\hline
\end{tabular}




\section{Profile of Roma and Non-Roma Groups Regarding Cigarette Smoking Prevalence}

Data on the prevalence of cigarette smoking in Roma $(\mathrm{N}=174)$ and non-Roma $(\mathrm{n}=131)$ children and adolescents, divided by gender and age, is shown on Table 1.

We found that 19\% (58) of the smoking subjects (of all 305 examined) were children.

A major part of smoking children and adolescents consisted of Roma probands $(79.3 \%, 46$ subjects; control sample $-20.7 \%$, 12 subjects). The average number of daily smoked cigarettes was 3.69 (3.87 in Roma and 3.38 in non-Roma participants). Of Roma boys $33 \%$ were smokers versus $19.8 \%$ of Roma girls and $7.5 \%$ of non-Roma boys and $10.9 \%$ of non-Roma girls. Results show interesting differences in the prevalence of cigarette smoking in relation to gender in both ethnic groups.

In children (7-11 years of age) we noted that 2 Roma boys, 1 Roma girl and 1 non-Roma girl smoke. Among adolescents (12-18), the number of smokers is considerably higher in both ethnic groups, notably higher in Roma (36.8\%) compared to non-Roma. In the control group, a higher prevalence of cigarette smoking was noted in females (16.2\%).

$67.8 \%$ of Roma parents of the examined children smoke compared to $38.9 \%$ non-Roma parents. Only $32.8 \%$ Roma parents were not smoking (one third), in contrast to the control group (no level of significance). This may consequently influence smoking habits in children and adolescents.

\section{Cigarette Smoking Related to Other CVD Risk Pre- dictors}

Values of biochemical and anthropometric risk predictors of CVD in examined smoking and non-smoking participants $($ mean $\pm \mathrm{SD}$ ) are illustrated in Table 2 (the data's analysis was guided by the concentration and values recommended by the Czech Atherosclerosis Society).
Smoking Roma have higher means of TG, Lp(a) levels, lower means of apo A and HDL-C level and higher means of BMI, WHR, sBP and dBP compared with non-smoking Roma. We noted that low serum levels of HDL-C was the most frequent risk factor in smoking Roma participants contrary to half of the control-group smokers, followed by high serum levels of $\mathrm{Lp}(\mathrm{a})$, low apo A, high WHR and high TG. Cigarette smoking had no influence on LDL-C or apo B levels. The correlation between cigarette smoking and risk of the increase of anthropometric values and modification of lipid profile in Roma and non-Roma probands was evaluated by the Fisher exact test. Cigarette smoking significantly lowered levels of protective antiatherogenic HDL-C $(\mathrm{p}=0.002)$ and apo $\mathrm{A}(\mathrm{p}=0.007)$ in Roma participants and increased values of WHR in non-Roma $(\mathrm{p}=0.02)$.

\section{DISCUSSION}

This study deals with the prevalence of cigarette smoking and its relation to other CVD risk predictors according to ethnic, gender and age differences in Roma and non-Roma children and adolescents from central Slovakia. In this biethnic study, 26.4\% of the Roma children and adolescents (more than twice opposite the control group) smoked. The majority of smokers among both ethnicities were Roma (79.3\%). Smoking Roma have higher means of TG, Lp(a) levels, lower means of apo A and HDL-C level and higher values of BMI, WHR, sBP and dBP compared with non-smoking Roma. The most frequent CVD risk predictors of smoking Roma probands was low serum levels HDL-C, apo A (the Fisher test confirmed a significant relationship between cigarette smoking and HDL-C, apo A; ${ }^{* *} \mathrm{p}<0.01$ ), high values of WHR, high serum levels of $\mathrm{Lp}(\mathrm{a})$ and TG.

We noted a higher prevalence of cigarette smoking among Roma boys (33\%) than girls $(19.8 \%)$ (while in contrast, nonRoma girls smoked more (10.9\%) than non-Roma boys $(7.5 \%))$

Table 2. Biochemical and anthropometric risk predictors of CVD in examined smoking and non-smoking participants (mean $\pm S D$ )

\begin{tabular}{|c|c|c|c|c|c|c|}
\hline Parameter & $\begin{array}{l}\text { Smoking Roma } \\
\quad(\mathrm{N}=46)\end{array}$ & $\begin{array}{c}\text { Non-smoking } \\
\text { Roma } \\
(\mathrm{N}=128)\end{array}$ & $p$ & $\begin{array}{c}\text { Smoking } \\
\text { non-Roma } \\
(\mathrm{N}=12)\end{array}$ & $\begin{array}{c}\text { Non-smoking } \\
\text { non-Roma } \\
(\mathrm{N}=119)\end{array}$ & $p$ \\
\hline $\mathrm{TC}(\mathrm{mmmol} / \mathrm{l})$ & $3.63 \pm 0.65$ & $3.93 \pm 0.64$ & & $3.41 \pm 0.59$ & $4.11 \pm 0.65$ & \\
\hline TG (mmol/l) & $0.99 \pm 0.54$ & $0.93 \pm 0.49$ & & $0.94 \pm 0.37$ & $0.98 \pm 0.54$ & \\
\hline LDL-C (mmol/l) & $2.03 \pm 0.52$ & $2.29 \pm 0.49$ & & $1.94 \pm 0.44$ & $2.47 \pm 0.57$ & \\
\hline $\mathrm{HDL}-\mathrm{C}(\mathrm{mmol} / \mathrm{l})$ & $1.06 \pm 0.26$ & $1.19 \pm 0.24$ & 0.002 & $1.04 \pm 0.16$ & $1.22 \pm 0.29$ & \\
\hline apo A $(g / l)$ & $1.19 \pm 0.27$ & $1.29 \pm 0.25$ & 0.007 & $1.13 \pm 0.09$ & $1.22 \pm 0.22$ & \\
\hline apo B $(g / l)$ & $0.66 \pm 0.15$ & $0.72 \pm 0.17$ & & $0.56 \pm 0.14$ & $0.71 \pm 0.17$ & \\
\hline Lp(a) (mg/l) & $299.2 \pm 344.06$ & $289.71 \pm 305.65$ & & $217.78 \pm 364.71$ & $157.41 \pm 214.55$ & \\
\hline $\mathrm{BMI}\left(\mathrm{kg} / \mathrm{m}^{2}\right)$ & $19.23 \pm 3.75$ & $17.99 \pm 3.71$ & & $23.71 \pm 5.76$ & $19.07 \pm 3.75$ & \\
\hline WHR & $0.85 \pm 0.07$ & $0.83 \pm 0.07$ & & $0.84 \pm 0.06$ & $0.81 \pm 0.05$ & 0.02 \\
\hline $\mathrm{sBP}(\mathrm{mmHg})$ & $111.5 \pm 11.89$ & $106.55 \pm 11.94$ & & $117.5 \pm 7.23$ & $106.13 \pm 10.88$ & \\
\hline $\mathrm{dBP}(\mathrm{mmHg})$ & $72.48 \pm 10.44$ & $67.83 \pm 8.92$ & & $77.5 \pm 8.12$ & $69.29 \pm 9.74$ & \\
\hline
\end{tabular}

Comparison of smokers and no-smokers within the same ethnic groups (the level of the statistic significance: ${ }^{*} p<0,05,{ }^{* *} p<0,01,{ }^{* * *} p<0,001$

Legenda: TC - Total Cholesterol, LDL-C - LDL-cholesterol, HDL-C - HDL-cholesterol, TG - triglycerides, apo A - apolipoprotein A, apo B - apolipoprotein B, Lp(a) -

Lipoprotein (a), WHR - Waist to Hip Ratio, BMI - Body Mass Index, sBP - sytolic Blood Pressure, dBP - diastolic Blood Pressure 
and among Roma adolescents (36.8\%) compared with non-Roma (14.5\%). Roma parents smoke very frequently (67.8\%) as well. Roma are an ethnic minority originating in northern India and living in Europe, including Slovakia. It has been assumed that about 400,000 and up to 500,000 Roma live in Slovakia, i.e. they represent $8.5 \%$ of the country's population, with rather high birth rate (non-Roma Slovak inhabitants have on average 151 children/1,000 families and Roma have 420 children/1,000 families (9).

Many studies demonstrate a very high prevalence of cigarette smoking in Roma, even at an early age. Zacharová (2003) found a higher prevalence of cigarette smoking in adult Roma compared to the control group. Often, cigarette smoking in the Roma population, which correlates with low life span (10), leads to a high occurrence of CVD (11). The influence of cigarette smoking on CVD development has been demonstrated by the Framingham Study (a three-times higher risk of ischaemic heart disease among smokers was shown) (12). A Nurses' Health Study (heavy women smokers -those who smoke 25 cigarettes/day- have a 5.5 times higher risk of fatal heart failure compared to non-smoking women) and the PDAY study (Pathobiological Determinants of Atherosclerosis in Youth) showed the relationship between cigarette smoking and atherosclerotic lesion development (13). A high prevalence of cigarette smoking is documented in Roma families (70.6\% of Roma men and $73.2 \%$ of Roma women live in families in which at least one member regularly smokes, and at least one parent $82.4 \%$ of men and $63.4 \%$ of women smoke regularly) (14). As passive smokers, Roma children and adolescents face a higher risk of atherosclerosis onset, accelerated by environmental tobacco smoke (ETS). Studies have shown: analyzed serum level of peroxide and index of oxidative stress leading to pathogenesis of atherosclerosis is significantly higher and serum antioxidant response is lower in children exposed to ETS (15) and negatively affects endothelial function (16); the decrease of HDL-C, an increase of thrombocyte aggregation and endothelial dysfunction was noted in healthy adolescents exposed to ETS (17). The influence of parents' smoking habits on their offspring (and further development of CVD) (18) was shown in the high prevalence of smoking in Roma youth. The effect of passive smoking may later lead to the rise of CVD risk factors in the population of Roma children as well. The over-25\% smoking segment of the Roma population and alarmingly an early start of cigarette smoking (in comparison with the general population) represent a significant factor in overall prevalence of smoking in Roma population. Looking at gender, there are differences in prevalence of cigarette smoking between females and males. Swedish, French and Canadian girls smoke more cigarettes than boys, which is similar to our control group. According to Zacharová, Roma males smoke more frequently than females $(60.3 \%$ of Roma men smoke and $41.5 \%$ of Roma women smoke, and men smoking on average 18.9 cigarettes/daily and women 16.8). Roma starts to smoke at the age of 17.3 in average however our results indicated commencement at earlier ages.

The number of smokers is growing most significantly in adolescents: regular smoking begins in pubescence, and the Fricela Study noted a $28 \%$ prevalence of smoking in early adulthood, (19). Similarly, ESPAD Project (2008-2010) documented 29\% prevalence of cigarette smoking in adolescents (among 15-16 year old students) in the European countries : 45\% in Austria, $41 \%$ in Czech Republic, 37\% in Slovak Republic, 35\% in Russia, 33\% in Hungary, 31\% in Ukraine, 29\% in Slovenia \& Estonia, 25\% in Romania, $21 \%$ in Poland, (20).

Based on data of WHO covering the period $1997 / 98,50 \%$ of Slovak boys and $27 \%$ of Slovak girls initiated smoking at the age of $11,74 \%$ of Slovak boys and $52 \%$ of Slovak girls at 13 and $80 \%$ of Slovak boys and $67 \%$ of Slovak girls at the age of 15 ).

Slovakia thus assumed a leading place in a European evaluation of the youth first contact with nicotine.

A significant relationship between cigarette smoking and low serum levels of HDL-C and apo A was shown. The Bogalusa Study confirmed the influence of cigarette smoking on HDL-C in girls and development of CVD in young women who had started to smoke at an early age (21). Cigarette smoking lowered HDL-C in older Italian, Finnish and Dutch men (aged 65-84) (22). The PDAY Study showed that second- and third-degree atherosclerotic lesions correlated with low HDL-C and cigarette smoking. The National Cholesterol Education Program (NCEP) points out at the relationship of nutrition and blood pressure in smoking adolescents. In general the Roma's diet features high consumption of saturated fatty acids, lipid and cholesterol, which even more prevails in smoking Roma adults and may likely have a negative impact on their smoking children.

Roma are classified as a socially disadvantaged segment of the Slovak population (resulting from their high unemployment rate) and the most prominent poverty risk group in many Central and Eastern European countries (poverty rates are more than 6 times higher copmpared to Caucasians) (23), which correlates with a high occurrence of cigarette smoking and its associated consequences for younger generations. Socioeconomic indicators in Tianjin, the third-largest Chinese city, show a significantly higher prevalence of cigarette smoking in poorer inhabitants $(67.9 \%$ men and $14.3 \%$ women, 24). Men with the lowest incomes were 1.4 times more likely to smoke compared to those with higher incomes. Women with a lower socioeconomic status tended to be regular smokers and smoked more cigarettes in general. Association of low socio-economic status with higher prevalence of cigarette smoking (compared with non-Roma) in Roma children and adolescents living in poverty emphasize the risk of the early onset and development of the atherogenic process. According to the report, Roma youth smoke more and are expected to suffer more often from atherosclerosis in the adult age.

Lower levels of education among Roma (generally connected with less knowledge of healthy life-style habits, diet and the harmful effects of active and passive smoking) may influence the high prevalence of cigarette smoking and predisposition towards cardiovascular disease among their young people. Degree of education was a good predictor of cigarette smoking for both sexes (related to blood pressure in women) in the Chinese study. The least-educated men smoke the most cigarettes daily. Problems in behaviour and poor school attendance may be in Roma children causally connected with the high proportion of smokers in the examined population. According to the results of WHO's research in 1997/98, drinking of alcohol, hostility towards school, skipping school, meeting with friends are among the most common phenomena contributing towards cigarette smoking.

Some researchers have shown that smoking has a considerable influence on variation in plasma lipid parameters (e.g. an inverse effect on serum electrolyte alterations in serum lipid profile). Nicotine causes an increase in TG, cholesterol levels 
and a decrease in HDL (increases circulatory pool of atherogenic LDL via accelerated transfer of lipids from HDL and increases the accumulation of LDL deposits on arterial walls (25). Increased serum calcium levels of smokers correlate negatively with serum HDL and positively with LDL. Cigarette smoke contains various oxidants (oxygen free radicals and volatile aldehydes) which are probably the major cause of damage to biomolecules (the oxidative process in the etiopathogenesis of atherosclerosis) (26).

By Kalio (2007), passive exposure to tobacco smoke has also been associated with decreased HDL, increased total cholesterol/ HDL ratio and an increase in platelet aggregation in children. The examined Roma active smoking group have significantly decreased antiatherogenic HDL (which plays a protective role through reverse transport of cholesterol, NO synthesis, and antioxidative and antiinflammatory effects on arteries). Furthermore, higher means of TG (tending towards an increase cholesterol and fatty streaks in the intima) and oxidized prothrombogenic and proatherogenic $\mathrm{Lp}$ (a) (retained in the intima and engulfed by macrophages accumulating in the atherosclerotic plaque) caused by cigarette smoking could be other biomarkers of the pathophysiological mechanism. In connection with the toxic effects of smoking on structural changes of the endothelium (tobacco smoke induces secretion of proinflammatory cytokine interleukin, can activate factor XII and affect fibrinogen and platelet function in thrombus formation, and stimulate proliferation of smooth muscle cells, leucocyte adhesion, and elevation of C-reactive protein), this may determine and predict a risk of the onset and developing atherosclerotic process in the Roma population as well.

Comparing the findings of the present study with those of Krajčovičová-Kudláčková (27), two important risk factors of atherosclerosis - smoking and dyslipidaemia are highly prevalent among the Roma minority.

The Framingham study confirmed the relationship between cigarette smoking, abdominal obesity, increase in blood pressure and pathological lipid profile and atherosclerotic plaques in adolescents. Signs of affected coronary arteries in conjunction with premature atherosclerosis are occurring at ever-earlier ages. The sooner children start smoking, the sooner the development of atherosclerosis begins.

The results of the research should answer the urgent question of the rate of cigarette smoking in children and adolescents. They mainly show a relationship between cigarette smoking and changed blood serum lipids levels, which can lead to an increase of CVD and other risk predictors. We recommend development of effective preventative health education programs for Roma (who live in a higher-risk environment compared to the majority population) in order to stem the spread of CVD as well as morbidity and mortality in this ethnic group living in Slovakia.

Abbreviations: CVD - Cardiovascular Disease, TC - Total Cholesterol, LDL-C - LDL-cholesterol, HDL-C - HDL-cholesterol, TG - Triglycerides, apolipoprotein A - apo A, apolipoprotein B - apo B, Lipoprotein a - Lp(a), BMI - Body Mass Index, WHR - Waist to Hip Ratio, BP - Blood Pressure, RF - Risk Factors, ETS - Environmental Tobacco Smoke

\section{Acknowledgements}

The authors thank the director of the Department of Clinical Biochemistry, F. D. Roosevelt Faculty Hospital in Banská Bystrica for the possibility of biochemical analyses
Research was performed with the financial support of the grants UMB no. 984/2002, UMB no. 1251 and VEGA 1/2345/05 for epidemiological examinations of the Roma population from Central Slovakia.

\section{REFERENCES}

1. Sierakowska-Fijałek A, Kaczmarek P, Pokoca L, Smorag I, WosikErenbek M, Baj Z. Homocystein serum levels and lipid parameters in children with atherosclerosis risk factors. Pol Merkur Lekarski. 2007 Feb;22(128):146-9. (In Polish.)

2. Šamánek M, Urbanová Z. Prevention of atherosclerosis in childs' age. Praha: Galén; 2003. (In Czech.)

3. Heitzer T, Meinertz T. Prevention of coronary heart disease: smoking. Z Kardiol. 2005;94(3):30-42.

4. Van Cleemput P, Parry G. Health status of Gypsy travellers. J Public Health Med. 2001 Jun;23(2):129-34.

5. Kačala O, Ginter E, Kovačic V, Kudláčková M, Valachovičová M. The comparison of Slovak, Magyar and Roma nutrition on ethnic - mixed land of Slovakia. Med Monitor. 2002;1:22-4. (In Slovak.)

6. Hujová Z, Desatnikova J, Gabor D. Some cardiovascular risk factors in Gypsy children and adolescents from Central Slovakia. Bratisl Lek Listy. 2009 April;110(4):233-9.

7. Šimurka P, Datel'ová M. Primary prevention of atherosclerosis in child's age. Martin: Osveta. 2004. (In Slovak.)

8. Labmed [Internet]. Košice: Labmed; 2006 [cited 2010 Mar 12]. Available from: www. labmed.sk. (In Slovak.)

9. Koupilová I, Epstein H, Holcík J, Hajioff S, McKee M. Health needs of the Roma population in the Czech and Slovak Republics. Soc Sci Med. 2001 Nov;53(9):1191-204.

10. Ginter E. What is the life span of Slovakian Gypsies? Med Monitor. 2002 May;5:16-7. (In Slovak.)

11. Vozarova de Courten B, de Courten M, Hanson RL, Zahorakova A, Egyenes HP, Tataranni PA, et al. Higher prevalence of type 2 diabetes, metabolic syndrome and cardiovascular diseases in gypsies than in nongypsies in Slovakia. Diabetes Res Clin Pract. 2003 Nov;62(2):95-103.

12. Morrison JA, deGroot I, Edwards BK, Kelly KA, Mellies MJ, Khoury P, et al. Lipids and lipoproteins in 927 schoolchildren, ages 6 to 17 years. Pediatrics. 1978 Dec;62(6):990-5.

13. Zieske AW, Malcom GT, Strong JP. Natural history and risk factors of atherosclerosis in children and youth: the PDAY study. Pediatr Pathol Mol Med. 2002 Mar-Apr;21(2):213-37.

14. Zacharová M. Global risks of atherosclerosis in Gypsy population in Slovakia. Bratislava; 2003. (In Slovak.)

15. Kosecik M, Erel O, Sevinc E, Selek S. Increased oxidative stress in children exposed to passive smoking. Int J Cardiol. 2005 Apr 8;100(1):61-4.

16. Kallio K, Jokinen E, Raitakari OT, Hämäläinen M, Siltala M, Volanen I, et al. Tobacco smoke exposure is associated with attenuated endothelial function in 11-year-old healthy children. Circulation. 2007 Jun 26;115(25):3205-12.

17. Halcox JP, Deanfield JE. Childhood origins of endothelial dysfunction. Heart. 2005 Oct;91(10):1272-4.

18. Tienboon P. Cardiovascular risk in the Asia-Pacific region from a nutrition and metabolic point of view: lipid. Asia Pac J Clin Nutr. 2001;10(2):10811.

19. Paterno CA. Coronary risk factors in adolescence. The FRICELA study. Rev Esp Cardiol. 2003 May;56(5):452-8. (In Spanish.)

20. The European School Survey Project on Alcohol and Other Drugs. Data collection [Internet]. Stockholm: ESPAD; 2011 [updated 2011; cited 2011 March 12]. Available from: www.espad.org/sa/node.asp?node $=640$.

21. Berenson GS, Srinivasan SR, Hunter SM, Nicklas TA, Freedman DS, Shear CL, et al. Risk factors in early life as predictors of adult heart disease: the Bogalusa Heart Study. Am J Med Sci. 1989 Sep;298(3):141-51.

22. Kromhout D, Nissinen A, Menotti A, Bloemberg B, Pekkanen J, Giampaoli S. Total and HDL cholesterol and their correlates in elderly men in Finland, Italy, and The Netherlands. Am J Epidemiol. 1990 May;131(5):855-63.

23. Alberty R, Albertyová D, Ahlers I. Distribution and correlations of nonhigh-density lipoprotein cholesterol in Roma and Caucasian children: the Slovak Lipid Community Study. Coll Antropol. 2009 Dec;33(4):1015-22.

24. Yu Z, Nissinen A, Vartiainen E, Song G, Guo Z, Zheng G, et al. Associations between socioeconomic status and cardiovascular risk factors in an urban population in China. Bull World Health Organ. 2000;78(11):1296-305. 
25. Akbari MZA, Bhatti MS, Shakoor M. Lipid profile in smoking. JAMC. 2000;12(3):19-21.

26. Padmavathi P, Reddy VD, Varadacharyulu N. Influence of chronic cigarette smoking on serum biochemical profile in male human volunteers. Journal of Health Science. 2009;55(2):265-70.
27. Krajcovicova-Kudlackova M, Blazicek P, Spustova V, Valachovicova M, Ginter E. Cardiovascular risk factors in young Gypsy population. Bratisl Lek Listy. 2004;105(7-8):256-9.

Received April 18, 2010 Accepted in revised form April 19, 2011 